\title{
Exercise and pregnancy in recreational and elite athletes: 2016 evidence summary from the IOC expert group meeting, Lausanne. Part 2-the effect of exercise on the fetus, labour and birth
}

\author{
Kari Bø, ${ }^{1}$ Raul Artal, ${ }^{2}$ Ruben Barakat, ${ }^{3}$ Wendy Brown, ${ }^{4}$ Michael Dooley, ${ }_{1}^{5}$ \\ Kelly R Evenson, ${ }^{6,7}$ Lene A H Haakstad, ${ }^{8}$ Karin Larsen, ${ }^{9}$ Bengt Kayser, ${ }^{10}$ \\ Tarja I Kinnunen, ${ }^{11}$ Michelle F Mottola, ${ }^{12}$ Ingrid Nygaard, ${ }^{13}$ Mireille van Poppel, ${ }^{14}$ \\ Britt Stuge, ${ }^{15}$ Gregory A L Davies, ${ }^{16}$ IOC Medical Commission
}

For numbered affiliations see end of article.

\section{Correspondence to}

Kari Bø, Department of Sport Medicine, Norwegian School of Sport Sciences, P.O. Box 4014 Ullevål Stadion, Oslo 0806, Norway; kari.bo@nih.no

Accepted 6 September 2016

\section{ABSTRACT}

This is Part 2 of 5 in the series of evidence statements from the IOC expert committee on exercise and pregnancy in recreational and elite athletes. Part 1 focused on the effects of training during pregnancy and on the management of common pregnancy-related symptoms experienced by athletes. In Part 2, we focus on maternal and fetal perinatal outcomes.

\section{BACKGROUND}

This is Part 2 of 5 in the series of evidence statements from the IOC expert committee on exercise and pregnancy in recreational and elite athletes. Part 1 focused on the effects of training during pregnancy and on the management of common pregnancy-related symptoms experienced by athletes. ${ }^{1}$ In Part 2, we focus on maternal and fetal perinatal outcomes.

Despite the maternal health benefits of exercise, there is a long-standing concern about the potential adverse effects of maternal exercise on the developing fetus, labour and birth outcomes. There remains apprehension that selective redistribution of blood flow to the exercising maternal muscles may result in inadequate fetal oxygenation leading to ominous fetal heart rate (FHR) changes and possibly miscarriage. There have been concerns that exercise-induced changes in uterine blood flow and an associated reduction in nutrient supply may impact fetal birth weight, particularly in women training at elite levels. Finally, there has also been concern that strenuous exercise increases the tone of the pelvic floor muscles possibly leading to prolonged labour, pelvic floor and perineal trauma and need for instrumental delivery and caesarean section. $^{2}$

\section{AIMS}

This evidence statement, based on a systematic literature search, examines how strenuous exercise affects the fetus. It also addresses issues relating to birth, such as risk of preterm birth, prolonged labour and mode of delivery, including injuries to the pelvic floor muscles and the perineum.

\section{METHODS}

For each section of this evidence statement, a search strategy was performed using search terms, including 'pregnancy' OR 'pregnant' OR 'postpartum' AND 'exercise' OR 'physical activity' OR 'leisure activity' OR 'leisure' OR 'recreation' OR 'recreational activity' or 'physical fitness' OR 'occupational activity' AND terms related to the condition under study (eg, 'cesarean section', 'miscarriage'). Available databases were searched, with an emphasis on PubMed, Embase, Cochrane, PEDro, Web of Science and SPORTDiscus. In addition, existing guidelines with reference lists were scanned.

With regard to lifting (strength training), we draw on leisure-time and occupational studies to inform the review. However, there is a downside that occupational studies include select populations. The review of each topic followed the following order: prevalence of the condition in the general pregnant or postpartum population, prevalence in high-level exercisers or elite athletes, risk factors in the general population and in relation to exercise and sport, and effect of preventive and treatment interventions. The level of evidence and the grade of recommendations are according to the Cochrane handbook (table 1) for prevention and treatment interventions only. Given this paper addresses pregnancy, where sex is not specified assume that we refer to women.

Each member of the working group acted as a lead author of one or more topics and 1-3 other members were assigned to review each topic. A first full consensus draft was reviewed before and during the 3-day IOC meeting (27-29 September 2015), and a new version of each topic was submitted to the meeting chairs (KB and $\mathrm{KMK}$ ) shortly after the meeting. Each topic leader made amendments before sending a new version for comments to the working group.

\section{THE EFFECT OF EXERCISE ON THE FETUS}

In this section, we consider the effects of exercise on FHR, risk of miscarriage, fetal growth, risk of preterm birth and Apgar scores at birth.

FHR and activity response to maternal exercise Normal baseline FHR is between 110 and $160 \mathrm{bpm}^{3}{ }^{3}$ FHR $<110 \mathrm{bpm}$ is recognised as fetal 
Table 1 Levels of quality of a body of evidence in the GRADE statement

\begin{tabular}{ll}
\hline Underlying methodology & $\begin{array}{l}\text { Quality } \\
\text { rating }\end{array}$ \\
\hline $\begin{array}{l}\text { Randomised trials; or double-upgraded observational studies } \\
\begin{array}{l}\text { Downgraded randomised trials; or upgraded observational } \\
\text { studies }\end{array}\end{array}$ & $\begin{array}{l}\text { High } \\
\text { Moderate }\end{array}$ \\
$\begin{array}{l}\text { Double-downgraded randomised trials; or observational studies } \\
\text { Triple-downgraded randomised trials; downgraded observational } \\
\text { studies or case series/case reports }\end{array}$ & Low \\
\hline
\end{tabular}

bradycardia and that $>160 \mathrm{bpm}$ is recognised as fetal tachycardia. FHR variability, with an amplitude of 6-25 bpm from baseline, is considered to be normal variability and is linked to fetal well-being. For example, at $<32$-week gestation, FHR accelerations of $10 \mathrm{bpm}$ for $10 \mathrm{~s}$, and beyond 32 weeks, FHRs that peak $15 \mathrm{bpm}$ or more above baseline, are considered good predictors of adequate oxygenation and fetal well-being. This variability is a direct result of fetal maturation and a balance between the developing sympathetic and parasympathetic autonomic nervous systems. Minimal or absent variability has been linked to fetal metabolic acidaemia or hypoxia.

During maternal exercise, there is an increase in the secretion of catecholamines and, as a result, a redistribution of blood flow, preferentially to the exercising muscles. In non-pregnant women at rest, $\sim 20 \%$ of the blood flow is directed to the muscles and $\sim 26 \%$ to the splanchnic organs, including the uterus. During strenuous exercise, $88 \%$ is redirected to the muscles and $<2 \%$ to the splanchnic organs. ${ }^{4}$ While these blood flow measures differ according to measurement methodology, and have not been confirmed during pregnancy, it is clear that blood flow during exercise is preferentially redirected to the working muscles.

Maternal exercise, regardless of intensity, triggers an increase in FHR; on average, by $10-15 \mathrm{bpm}$. This could reflect a protective mechanism for fetal well-being. ${ }^{3}$ 5-9 FHR accelerations in excess of $15 \mathrm{bpm}$, lasting $>15 \mathrm{~s}$, reflect adequate fetal oxygenation and an umbilical arterial $\mathrm{pH}>7.2$. In contrast, repetitive variable or late FHR decelerations usually reflect placental dysfunction, umbilical cord compression fetal distress or other conditions. Rapid onset and offset in FHR reflects vagal responses. However, in the absence of variability, these changes may indicate fetal hypoxia. Episodes of maternal hypoxaemia first cause transient FHR accelerations but if hypoxia persists, the fetus will develop bradycardia.

There are several reports of abnormal FHR recordings during strenuous exercise. Some of the recordings were interpreted as artefacts, caused by the ultrasound Doppler transducers recording periodic pacing/movements of the exercising mothers rather than FHRs. ${ }^{5-7}$ However, in one report, three cases of bradycardia occurred during exertion at $90 \%$ of $\mathrm{VO}_{2}$ max, which persisted at rest. ${ }^{10}$ In another report, FHR decelerations were recorded during and immediately post exercise in five cases and were interpreted as being caused by an exercise intensity that interfered with umbilical blood flow; some of these events were associated with elevated umbilical and uterine Doppler. ${ }^{11}$ Six Olympic-level athletes who were pregnant at 23-week to 29-week gestation ran 3-5 submaximal workloads on a treadmill at $60-90 \%$ of $\mathrm{VO}_{2}$ max. Once the women reached $90 \%$ or more of their maximal heart rate, fetal bradycardia occurred, and there was a high umbilical artery pulsatility index (PI) when the women exercised. These findings may suggest that high intensity exercise could compromise fetal well-being. ${ }^{12}$

Labour and delivery are physiologically challenging events for the fetus and mother. A pilot study was conducted to evaluate FHR responses to maternal exercise during labour, after the fetal membranes were ruptured. The recordings were obtained by direct fetal monitoring, with electrodes attached to the fetal scalp. ${ }^{13}$ Two Olympic-level athletes, who exercised strenuously daily throughout pregnancy, also exercised during their active phase of labour. During labour, the athletes performed a submaximal $\mathrm{VO}_{2}$ test (at $60 \%$ of their known $\mathrm{VO}_{2} \max$ ) for 4 and $4.5 \mathrm{~min}$. The FHR recorded was normal prior to, during and after the exercise. Both athletes delivered vaginally and had no labour complications; the newborns had Apgar scores of 9 and 10 at 1 and $5 \mathrm{~min}$. The newborns were developing normally when evaluated at 6 weeks of life. The combined effect of uterine activity during labour and moderate/strenuous exercise did not alter the uterine/placental perfusion or reserve, to trigger FHR abnormalities.

In all of these studies, FHR decelerations were transitory, and the FHR was typically returned to normal when exercise stopped. Although decelerations have been reported to occur during and after exercise, brief heart rate decelerations are rare and sporadic, and are thought to be inconsequential. ${ }^{5-10}$ No neonatal abnormalities in relation to these occurrences have been reported.

Level of evidence: although some of these studies in this area have been conducted in elite athletes, the studies are mostly case studies/series and the quality of evidence is therefore rated as very low.

\section{Risk of miscarriage \\ Definition}

Miscarriage (ie, spontaneous abortion or pregnancy loss) is the loss of a pregnancy during the first 20 weeks of the pregnancy.

\section{Prevalence}

Miscarriage is frequent, $>10 \%$ in the general pregnant population, of which $80 \%$ occur in the first trimester (Committee on Practice Bulletins-Gynecology, 2015). ${ }^{14}$ The risk of miscarriage is most dependent on maternal age, with women $<35$ years having a risk of $5-7 \%$ and women over 40 years having a risk of $22 \% .^{9}$ The risk is higher with fertility treatment, but the major cause of miscarriage remains chromosomal abnormalities of the fetus. Independent of training routine, like all pregnant women, female athletes may also sustain a miscarriage. The question is whether a strenuous exercise routine increases the risk of miscarriage?

\section{Strenuous activity and miscarriage}

In a cohort of 92671 women, of whom 3187 had experienced a miscarriage, 2551 were interviewed about their exercise habits. ${ }^{15}$ Data on exercise were obtained either during pregnancy or after an early miscarriage (<gestational week 22). HR was estimated for gestational week $<11,11-14,15-18$ and 1922. The risk of miscarriage increased as the amount of exercise increased to a $\mathrm{HR}$ (ie, instantaneous risk over the study period) of 3.7 (95\% CI 2.9 to 4.7) for women who exercised for $>7$ hours/week compared to non-exercisers. High-impact exercise (jogging, ball games and racquet sports) was associated with an increased risk of miscarriage of HR 3.7 (95\% CI 2.9 to 4.7). However, there was no association between exercise and the risk of miscarriage after 18 -week gestation. In light of the potential for recall bias, evidence of a dose-response 
relationship between high-impact leisure-time exercise and early miscarriage is limited. ${ }^{15}$

Where there may be an increased risk for miscarriage is when there is intense exercise at the time of implantation. ${ }^{16}$ In a prospective study in which women planning first pregnancy were followed from termination of birth control until pregnancy (for up to six menstrual cycles), 162 women reported 181 pregnancies. Using prospectively collected structured diaries, the adjusted risk ratio (RR) for miscarriage was higher in women who reported higher than average physical strain on days 6-9 after the estimated date of ovulation (RR 2.5, 95\% CI 1.3 to 4.6). There was no association with weekly average daily activity scores, suggesting that it was the intensity of the effort(s) around the implantation phase that was associated with the risk of miscarriage. The scant epidemiological data suggest that highimpact or high strain physical activity may be associated with a slightly higher risk of miscarriage during the fetal implantation phase.

Level of evidence: for a negative effect of strenuous exercise on miscarriage is low to moderate.

\section{Lifting and miscarriage}

In a large cohort of 71500 women with 2886 miscarriages, the adjusted risk of early miscarriage (before 13 weeks) increased with increasing frequency of daily lifts and total burden lifted per day at work. ${ }^{17}$ The HRs were 1.38 (95\% CI 1.10 to 1.74 ) for a total weight load per day of $101-200 \mathrm{~kg}$, and $2.02(95 \%$ CI 1.23 to 3.33 ) for a daily weight load $>1000 \mathrm{~kg}$, both compared with non-lifters. Late miscarriage (defined as 1321 weeks) was associated with total daily load, but not with the number of lifts per day. There was no association between occupational lifting and stillbirth $>22$ weeks. ${ }^{18}{ }^{19}$ Similarly, a retrospective study in 1752 women working in the textile industry found an increased risk of self-reported miscarriage in women who repeatedly worked in a crouching position (OR 1.82, 95\% CI 1.14 to 2.93$),{ }^{20}$ compared to women in sedentary jobs. Women whose work provided light or medium physical activity had a lower risk of miscarriage.

Level of evidence: for a negative effect of lifting on miscarriage is low to moderate.

Light-to-moderate physical activity and miscarriage

A systematic review ${ }^{21}$ concluded that light to moderate intensity leisure-time physical activity does not increase the risk of miscarriage and may perhaps decrease it. There was limited evidence that leisure-time light-to-moderate physical activity and occupational physical activity (work related or household) may relate differently to miscarriage, although data are insufficient to draw robust conclusions.

Overall, it appears that in the general population, regular light-to-moderate physical activity does not increase the risk of miscarriage and may decrease the risk of miscarriage. ${ }^{22}$ There may be special circumstances related to the performance of strenuous exercise around the implantation period that may increase the risk of miscarriage. ${ }^{16}$

Level of evidence: in the absence of studies in elite athletes, female athletes who want to become pregnant may consider limiting the intensity of high-impact training routines in the week after ovulation, and refraining from repetitive heavy lifting efforts in the first trimester of pregnancy. However, these recommendations are based on low quality studies.

\section{Fetal growth and the newborn's birth weight}

In non-pregnant athletes, high intensity exercise is associated with redistribution of blood flow away from the splanchnic organs towards the skeletal muscles. To meet the needs of the developing fetus, blood flow to the uterus during pregnancy increases from $50 \mathrm{ml} / \mathrm{min}$ in the first trimester to $500 \mathrm{ml} / \mathrm{min}$ in the third trimester. Therefore, there is a theoretical concern that regular, strenuous exercise in pregnancy, resulting in temporary redistribution of a portion of this blood flow, may impair fetal growth.

This theory has been proved in numerous animal species using forced exercise. ${ }^{21}$ However, the impact of maternal exercise on newborn birth weight in humans is less clear. A Cochrane review of 14 trials (1014 women) ${ }^{23}$ reported no significant change in birth weight with exercise. Moderate intensity exercise may reduce the risk of large-for-gestational-age and small-for-gestational-age babies. ${ }^{24}$ Regular strenuous exercise, particularly during the last trimester, generally leads to a lower birth weight $(\sim 200 \mathrm{~g})$ than if not exercising (ref.). This lower birth weight reflects lower fat mass but a greater lean mass in newborns of exercisers, compared to non-exercisers. ${ }^{24}$

There is heterogeneity in the exercise regimens, including type, frequency and intensity of exercise of pregnant women. ${ }^{25}$ In contrast to sedentary women, those who exercised during pregnancy had a $31 \%$ lower risk of having a newborn $>4000 \mathrm{~g}$ or $>90$ th centile for gestational age $(95 \%$ CI 0.55 to 0.86$) .{ }^{25}$ Although the offspring of exercising women were, on average, $31 \mathrm{~g}$ smaller than those of inactive women ( $95 \% \mathrm{CI}-57$ to $-4 \mathrm{~g})$, there was no difference in the rate of having a baby $<2500 \mathrm{~g}$ or less than the 10 th centile for gestational age (OR 1.02, 95\% CI 0.72 to 1.46 ). ${ }^{25}$

Clinical trials examining the effect of exercise on newborn birth weight have prescribed exercise regimens of at least 2-3, 30 min sessions per week. These regimens may not be strenuous enough to elicit the effects seen in animal models. There are no published trials evaluating newborn birth weight in elite athletes. Although the minor decrease in newborn weight is unlikely to be clinically significant following the exercise regimens used in the populations studied, caution is advised when extrapolating that minor impact to the elite athlete who exercises at a much higher frequency and intensity. Reducing the rate of macrosomia reduces the risk of shoulder dystocia, caesarean section, and childhood obesity. ${ }^{26} 27$

Level of evidence: high level of evidence that exercise during pregnancy reduces excessive birth weight, but lack of studies in elite athletes.

\section{Physical activity and preterm birth}

Definition

Preterm birth is defined as birth of a live-born infant prior to the completion of 37-week gestation (World Health Organization, 2012). Preterm birth can be categorised according to gestational age, aetiological pathway and clinical presentation. $^{21}$

\section{Prevalence and impact of preterm birth}

An estimated 15 million babies ( $>10 \%$ of babies) are born preterm each year, and in most countries, the rates are rising. ${ }^{28}$ This is, in part, due to improvements in antenatal care and care during labour, which improve survival of preterm infants that would otherwise not have survived. In addition, $>1$ million babies die due to complications from preterm birth, making it the leading cause of newborn death and the second leading cause 
of death in children aged $<5.2829$ Many other children are affected by disabilities resulting from their premature delivery.

Physical activity and preterm birth

The literature on physical activity and preterm birth is often separated by physical activity mode (occupational vs leisure), since findings tend to differ.

Observational studies—occupational physical activity: There remains some controversy in the literature regarding the impact (if any) of occupational physical activity (eg, long periods of standing, walking or lifting) on the risk of preterm birth. Studies reporting an effect of physical activity consistently show this effect to be low (absolute increase in risk of 1-4\%). ${ }^{30-34}$

Observational studies-leisure-time physical activity: In the general obstetric population, there is no evidence of an association between leisure-time physical activity or exercise, and an increased risk of preterm birth. ${ }^{21} 32-50$

Most observational studies have not reported strenuous leisure-time physical activity. For studies that had sufficient statistical power to explore strenuous leisure activity (typically as any vs none), there was no effect or a modestly reduced risk of preterm birth. ${ }^{48} 50-52$

One small study exists describing preterm birth and physical activity among athletes. ${ }^{53}$ Among 131 well-conditioned recreational athletes with an uneventful first half of pregnancy, 87 continued to exercise regularly and 44 discontinued exercise before the second trimester. The incidence of preterm labour (not preterm birth) was similar in the two groups (9\%).

Randomised clinical trials: In 2010, a Cochrane review of 14 trials that compared women who performed aerobic exercise with those who did not with respect to the risk of preterm birth (1014 women) concluded that generally the trials were small and not of high methodological quality. ${ }^{23}$ Eleven trials reported on pregnancy outcomes and the pooled estimate was not statistically significant (relative risk (RR) 1.82; 95\% CI 0.35 to 9.57). Since then, at least six randomised trials have been published, with sample sizes ranging from $35^{54}$ to $320^{55}$ pregnant women.

In five of these recent studies, ${ }^{55-60}$ structured aerobic exercise classes were offered from early in pregnancy (8-week to 14-week gestation) to the end of pregnancy. Women in the intervention groups were compared to a usual care control group, with no differences in preterm birth rates between the groups in any study. In another study, sedentary women assigned to water aerobics had a similar risk of preterm birth to sedentary controls (RR $0.84 ; 95 \%$ CI 0.28 to 2.53 ). ${ }^{61}$

Level of evidence: moderate quality evidence, from randomised clinical trials (RCTs) and observational studies, to suggest that there are few effects of exercise on preterm birth rate in the general population. There have been no studies of elite athletes.

\section{Apgar score}

The Apgar score is a tool used by healthcare providers to evaluate the early neonatal adaptation to the extrauterine environment. ${ }^{57}$ Apgar scores are commonly assigned at 1 and $5 \mathrm{~min}$ following birth, and evaluate the following neonatal characteristics: colour, heart rate, reflex irritability, muscle tone and respiration. The Apgar score has not been correlated with long-term development outcomes. ${ }^{60}$ Although, an Apgar score of $0-3$ at 5 min may correlate with an increased risk of mortality. ${ }^{62}$

Few studies (although none in elite athletes), with low numbers of participants, have evaluated the impact of exercise on Apgar scores. There were conflicting results in two randomised studies of previously sedentary nulliparous women who received either usual care or a structured exercise programme. In one study, there was no difference in the mean Apgar scores at $1 \min (7.5 \pm 1.3$ vs $8.0 \pm 0.8, \mathrm{p}=0.31)$ or $5 \min (9.4 \pm 0.6$ vs $9.6 \pm 0.4, p=0.08$ ) between the control and exercising groups, ${ }^{63}$ whereas in the other study the 1- and 5-min Apgar scores were higher in the exercising group $(p=0.036$ and 0.015 , respectively). ${ }^{64}$

Level of evidence: there is moderate evidence of no effect of exercise on Apgar score in the general population and no studies in elite athletes.

\section{THE EFFECT OF EXERCISE ON DELIVERY}

In this section, we consider the effect of exercise on the need for intervention in delivery.

\section{Induction of labour, episiotomy and epidural anaesthesia}

Population rates for induction of labour, episiotomy and epidural anaesthesia vary considerably by geographic location. Current rates for induction of labour in the USA, UK and Australia are between 20\% and 25\%. ${ }^{6163}$

Rates of episiotomy, a procedure long considered 'standard care' in the USA and some other countries, have begun to decrease in many parts of the world. Despite this, variability is high-between 1995 and 2003, episiotomy rates ranged from 9.7\% in Sweden to an estimated $100 \%$ in Taiwan. ${ }^{65}$ In the USA, rates have changed substantially, from $60.9 \%$ of all vaginal deliveries in 1979 , to $24.5 \%$ in 2004 . A review of vaginal deliveries not complicated by shoulder dystocia, fetal distress and FHR abnormalities from 510 US hospitals showed a continued drop in episiotomy rates-17\% in 2006 and $12 \%$ in $2012 .{ }^{66}$ Similarly, anal sphincter laceration has decreased from $5 \%$ to $3 \%$ during the same time period. ${ }^{67}$

Based on eight randomised trials, a Cochrane review concluded that, compared to routine episiotomy, restrictive episiotomy resulted in less severe perineal trauma (RR 0.67, 95\% CI 0.49 to 0.91 ), fewer healing complications (RR $0.69,95 \% \mathrm{CI}$ 0.56 to 0.85 ) and more anterior perineal trauma (RR 1.84, 95\% CI 1.61 to 2.10), but no differences in severe vaginal trauma, painful intercourse, urinary incontinence or pain. ${ }^{68}$ Results were similar for mediolateral and midline episiotomy.

According to 2008 data, in the USA, 61\% of women who delivered vaginally received an epidural or spinal anaesthetic. ${ }^{69}$ However, rates in many other developed countries are generally lower. $^{70}$

Risk factors for induction, episiotomy and epidural anaesthesia The increase in induction of labour has been attributed in large part to elective induction, which is motivated by a variety of reasons, from scheduling considerations to concerns for complications. ${ }^{71}$ Similarly, as highlighted by the summarised trends, episiotomy is also often elective in some regions, rather than indicated for fetal distress or other conditions requiring prompt delivery. The use of epidural anaesthesia depends on availability of this service, alternate methods of pain control available and the desires of women and their clinicians.

Induction, episiotomy and epidural anaesthesia and exercise There are data, including randomised trial data, about the effect of structured physical activity programmes during pregnancy on these outcomes in non-athletes. We identified no data regarding these birth events specifically in athletes.

Data from 16 RCTs that evaluated the effect of structured physical exercise programmes during pregnancy on the course of labour and delivery were insufficient to draw conclusions 
about episiotomy, epidural anaesthesia and induction of labour. ${ }^{72} 73$ Previously, sedentary women assigned to a light-intensity resistance exercise training during the second and third trimesters of pregnancy had similar rates of epidural anaesthesia to those seen in controls. ${ }^{67} 74$

In a secondary analysis of a trial in which pregnant women were randomly assigned to either a 12-week exercise programme, conducted between 20 -week and 36-week gestation, or standard care, there were no differences in the proportion of women who received epidural anaesthesia (36\% vs 38\%), oxytocin augmentation $(51 \%$ vs $50 \%)$ or episiotomy (31\% vs $24 \%)^{75}$

Level of evidence: there is moderate evidence that exercise does not increase rates of induction, episiotomy or epidural in the general population. No studies were found in elite athletes.

\section{Prolonged labour}

General muscular hypertrophy and increased muscle tone found in some elite athletes are assumed to predispose the athlete to a prolonged second stage of labour, during which the mother works to push. ${ }^{76}$ The untested assumptions behind this belief are that these athletes also have hypertrophied pelvic floor muscles that, in turn, block the ability of the fetus to descend during pushing. Scant data indicate that elite athletes do have larger pelvic floor muscles than non-athletes.

The cross-sectional area and width of the pubococcygeus muscle measured on MRI was greater in a group of 10 athletes compared with 10 controls. $^{77}$ Pertinent to successful vaginal birth, there were no differences between the two groups in the cross-sectional area of the urogenital hiatus (the opening through which the fetus passes). In pregnant women studied at 37-week gestation, compared with non-exercisers, those who exercised 30 or more minutes three times per week had a larger levator hiatus area at rest and during pelvic floor muscle contraction. ${ }^{78}$ Neither exercising the pelvic floor muscles specifically during pregnancy, nor pelvic muscle strength and endurance at midpregnancy, increases the risk of operative delivery or severe perineal lacerations. ${ }^{79}$ These findings call into question the hypothesis that exercising regularly causes a 'tighter' pelvic floor that might impede childbirth. Conversely, it is possible that stronger abdominal muscles found in athletes might allow more effective pushing and a shorter second stage of labour.

No studies were identified that specifically addressed duration of labour in elite athletes.

\section{Risk factors for prolonged second stage of labour}

Prolonged second stage of labour is generally defined in nulliparous women as $>3$ hours with epidural anaesthesia and $>2$ hours without epidural anaesthesia. In multiparous women, prolonged second stage is defined as $>2$ hours with epidural anaesthesia and $>1$ hour without epidural anaesthesia. In a recent large US study, a prolonged second stage occurred in 9.9\% and $13.9 \%$ of nulliparous women with and without epidural anaesthesia, and in $3.1 \%$ and $5.9 \%$ of multiparous women with and without epidural anaesthesia, respectively. ${ }^{80}$

Risk factors for a prolonged second stage include fetal head position that is not occiput anterior, fetal size, epidural anaesthesia and parity. ${ }^{81}{ }^{82} \mathrm{~A}$ systematic review of five studies, including 879 patients, ${ }^{83}$ concluded that data are insufficient to draw conclusions about the effect of body position during pushing in women with epidural anaesthesia on the duration of second stage or on the need for instrumented deliveries. ${ }^{84}$

Obesity, a clear risk factor for prolonged first stage of labour, appears to have less impact on the second stage of labour. ${ }^{85}$
Relationship between physical activity and the duration of labour Women who exercised during their pregnancies had similar lengths of labour as sedentary women. ${ }^{36}$ However, these exercise programmes were generally performed for 45 min per day 1-3 times per week and cannot be extrapolated to programmes of greater intensity. ${ }^{83} \mathrm{~A}$ recent systematic review of 16 RCTs that evaluated the effect of structured physical exercise programmes during pregnancy on the course of labour and delivery concluded that data were insufficient to draw conclusions regarding the effect of exercise on the duration of labour. ${ }^{86} 87$

Studies published since the previous systematic review may provide additional insights regarding the effect of physical activity on the course of labour and delivery. Pregnant women randomly assigned to either an exercise intervention involving a 1-hour physical conditioning programme three times weekly throughout pregnancy, or control had a shorter first stage of labour (389 vs $516 \mathrm{~min}$ ) but no difference in the second stage of labour. ${ }^{88}$ Having a higher $\mathrm{VO}_{2}$ during an exercise test performed at 35-37 weeks, a reflection of aerobic fitness was associated with a shorter duration of first stage of labour in 40 nulliparous women. ${ }^{36} \mathrm{~A}$ secondary analysis of a trial in which pregnant women were randomly assigned to either a 12-week exercise programme conducted between 20-week and 36- week gestation, or standard care, found no difference in the proportion of women with prolonged active second stage (included active pushing only). However, the exercise group had, on average, a longer, albeit clinically insignificant, second stage (44 compared to $38 \mathrm{~min}) .^{75}$

Taken together, these findings suggest that physical activity during pregnancy either decreases or has no effect on the duration of labour. $^{79} 89$

Level of evidence: there is moderate evidence that physical activity does not increase first or second stage of labour. We identified no data regarding prolonged labour specifically in elite athletes.

\section{Acute and elective caesarean delivery}

Teasing out differences between caesarean delivery rates by level of exercise is difficult, given the huge variation in caesarean rates globally. The WHO defined as the ideal caesarean delivery rate (the rate that balanced harms and benefits of performing or not performing caesarean) as between $10 \%$ and $15 \%$. Countries with caesarean rates below $10 \%$ were considered to show underuse, whereas countries with caesarean rates above 15\% were considered to show overuse. Fifty-four countries had caesarean rates below 10\%, whereas 69 had rates above 15\%. Fourteen countries had caesarean rates between $10 \%$ and $15 \% .^{90}$

\section{The effect of exercise during pregnancy on rates of caesarean delivery}

Primary risk factors for caesarean delivery include nulliparity, obesity (with a linear relationship between body mass index categories and risk), cervical dilation at admission to the labour unit, advanced maternal age and certain medical complications of pregnancy, such as pre-eclampsia. ${ }^{91}$

Several RCTs have shown no effect of moderate exercise on caesarean delivery. In one trial, previously sedentary women assigned to light-intensity resistance exercise training during the second and third trimesters of pregnancy had similar rates of caesarean delivery to controls $(15.3 \%$ vs $15.7 \%) .{ }^{92}$ In another trial that assessed the effect of a physical conditioning programme throughout pregnancy, there was also no difference in the incidence of caesarean delivery between those assigned to 
this programme and the controls $(11.7 \%$ vs $14.4 \%$ of women with follow-up). ${ }^{75}$

Cohort and cross-sectional studies suggest that moderate exercise either protects against caesarean delivery or has no impact on this outcome. ${ }^{51} 53 \quad 55 \quad 567588 \quad 92-94$ In a group of wellconditioned women who regularly performed aerobics or running before pregnancy, those who continued to exercise at or above $50 \%$ of their preconception level throughout pregnancy had a lower incidence of caesarean delivery than those who discontinued their regular exercise before the end of the first trimester (6\% vs 20\%). ${ }^{95}$ Similarly, pregnant women who self-selected into a high-level exercise group during pregnancy had a lower incidence of caesarean delivery $(6.7 \%$ vs $23.1 \%$ in the low exercise group, and $19.0 \%$ in the medium exercise group). ${ }^{96-98}$

In a cross-sectional study of 3006 women in the third trimester, those who reported exercising $150 \mathrm{~min}$ or more per week had no statistically significant reduction in the odds of caesarean delivery $(0.86$; $95 \%$ CI 0.69 to 1.07$)$ compared with those who exercised $<60 \mathrm{~min} /$ week. $^{53}$ In a cohort study of 1342 women who delivered at term, compared with women exercising less than once per week, there were no differences in the caesarean delivery rates of women who reported exercising 1-4 times per week (RR 0.89 ; $95 \%$ CI 0.69 to 1.15 ) or 5 or more times per week during the last 3 months of pregnancy (RR 1.04; 95\% CI 0.66 to 1.64) after adjustment for parity, gestational age and hypertension. ${ }^{93}$

Based on evidence from systematic reviews:

1. Overall, women in exercise groups had a lower risk of caesarean delivery (RR $0.85,95 \%$ CI 0.73 to 0.99 ). ${ }^{51}$

2. Low-to-moderate levels of physical activity during pregnancy among healthy pregnant women modestly increase the chance of normal delivery. ${ }^{99}$

Level of evidence: there is inconsistent evidence on the effect of exercise during pregnancy on caesarean section and no studies on elite athletes.

\section{Risk of pelvic floor injury}

In this section, we outline the evidence for pelvic floor injury during labour.

\section{The pelvic floor}

The pelvic floor provides the support needed to maintain continence and prevent pelvic organ prolapse. The structures of the pelvic floor include the bony pelvis, muscular and connective tissue supports and the endopelvic fascia. ${ }^{78}$ The muscular supports include the pelvic diaphragm, made up of the levator ani muscle (LAM) and coccygeus muscle as well as the urogenital diaphragm (also known as the perineal membrane), comprised of smaller perineal muscles. Terminology representing the LAM varies, but most nomenclature systems used include the pubococcygeus and ileococcygeus muscles in this muscle group.

\section{Definition of LAM defect}

The pubococcygeus muscle is the LAM most affected by vaginal birth. This muscle stretches more than three times its normal length during delivery of the fetal head ${ }^{88}$ and can also be injured by avulsion from its origin near the symphysis; related nerves may also be stretched. Avulsion injuries, also known as LAM tears or LAM defects, can be partial or complete and are often referred to as minor or major. Multiple definitions of LAM defect exist and definitions differ depending on the modality used to detect them (generally ultrasound and
MRI). ${ }^{100}$ Reproducibility varies widely and reliability is improved when observers trained by each other are used. ${ }^{101}$

Incidence of LAM defects

Ten to $20 \%$ of primiparous women demonstrate an LAM defect on MRI or ultrasound. ${ }^{102}$ We found no information about the incidence of LAM defect in athletes.

\section{Significance of LAM defect}

Since identifying LAM defects requires special expertise, research about these defects and clinical correlates is in its infancy. In the first year postpartum, LAM defects were associated with lower pelvic floor muscle strength, lower pelvic floor muscle endurance, various types of pelvic organ prolapse, urinary incontinence and a sense that the vagina was too loose, but not with fecal incontinence, fecal urgency or a sensation of a lump in the vagina. ${ }^{103-105}$

LAM defect is associated with significant pelvic organ prolapse in middle-aged women, ${ }^{104}{ }^{106-113}$ but data are inconclusive about whether LAM defect increases the risk for future stress urinary incontinence remote from delivery. ${ }^{114}$

\section{Risk factors for LAM defect}

This incidence of LAM defect increases to $50 \%$ in women whose deliveries were complicated by specific delivery variables, including forceps delivery, anal sphincter rupture, large fetal head circumference, increased fetal weight and prolonged second stage. ${ }^{113}$ We found no studies on whether physical activity is associated with LAM defect.

\section{LAM and LAM defects in athletes}

Scant data suggest that athletes have larger LAM than non-athletes, based on MRI or ultrasound measurements. ${ }^{102} 109$ 115-117 However, this may not correlate with increased LAM strength. In one study of a non-pregnant group, pelvic floor muscle strength, as assessed by manometer, was lower in a group of 30 athletes than in 10 non-athletes. ${ }^{77}$ We identified no data regarding LAM defects specifically in athletes.

\section{Risk of anal sphincter tear}

In this section, we outline evidence regarding anal sphincter injury during labour.

\section{Classification of perineal tears}

Anal sphincter tears (also known as third- and fourth-degree perineal tears) involve injury to the perineum that extend to at least part of the anal sphincter and may involve the entire external sphincter, internal sphincter and anorectal mucosa. ${ }^{118}$

\section{Incidence of anal sphincter tear}

The incidence of anal sphincter tear varies widely, depending on definition, method of ascertainment, diligence about detection and population studied, and generally ranges from $3 \%$ to 20\%. ${ }^{76} 119$

\section{Risk factors for anal sphincter tear}

Midline episiotomy is associated with a 3\% risk of anal sphincter injury. Consequently, a mediolateral approach is more commonly used when episiotomy is required. ${ }^{120-122}$ However, the angle of episiotomy matters. Suture angles of $40-60^{\circ}$ were in a 'safe zone' and reduced the risk of anal sphincter injury by 40 $50 \%$ compared with spontaneous tears. ${ }^{123}$ In addition to midline episiotomy, other risk factors for anal sphincter tear include first vaginal delivery, shorter perineal length, perineal 
oedema, instrumented deliveries, prolonged second stage of labour, birth weight $>4000 \mathrm{~g}$ and fetal occipitoposterior presentation. With the exception of forceps deliveries, which carry a $7 \%$ risk of anal sphincter tear, the other risk factors are associated with a $2-4 \%$ risk. $^{70}$

\section{Significance of anal sphincter injury}

Anal sphincter injury increases the risk of anal incontinence in the early and later postpartum periods. Six months after delivery, $23 \%$ of women with an anal sphincter tear reported bowel incontinence compared with $13.4 \%$ of controls. The incidence of worse bowel control was nearly 10 times higher in women with fourth-degree tears than in those with third-degree tears. ${ }^{124}$ Five to 10 years after childbirth, women who sustained an anal sphincter tear were 2.3 times (95\% CI 1.27 to 4.26) more likely to report anal incontinence than those who did not sustain a tear (19\% vs $10 \%){ }^{121} 124$ This increased risk attenuates in older age as other risk factors for anal incontinence take priority.

\section{Anal sphincter tear in athletes}

We identified no data on anal sphincter tears specifically in elite athletes. However, in a prospective cohort study, pregestational physical inactivity increased the risk of anal sphincter tears (found in 4.3\% of women delivered vaginally) sixfold (OR 6.1, 95\% CI 1.6 to 22.9) after adjusting for other factors. However, these data should be interpreted with caution as only 12 of 19 women with an anal sphincter tear completed information about pregestational physical inactivity. ${ }^{120}$ In contrast, a secondary analysis of data from a randomised trial in which pregnant women were randomly assigned either to a 12-week low-impact exercise programme that included pelvic floor muscle training conducted between 20 -week and 36-week gestation, or standard care, found no differences in the proportion of women who sustained an anal sphincter tear (6\% in both groups). ${ }^{125}$

\section{Prevention of anal sphincter tears}

Based on eight randomised or quasi-randomised trials involving 11651 women, a recent Cochrane review concluded that warm compresses (RR $0.48,95 \%$ CI 0.28 to 0.84 (two studies, 1525 women)) and perineal massage during labour (RR $0.52,95 \%$ CI 0.29 to 0.94 (two studies, 2147 women)) reduced the incidence of anal sphincter tears. ${ }^{126}$ Another Cochrane review that included four randomised or quasi- randomised trials (2497 women) concluded that antenatal digital perineal massage did not reduce the incidence of anal sphincter tears. ${ }^{79}$

Level of evidence: there are no studies on the effect of regular exercise during pregnancy for the prevention of LAM or perineal tears, and no studies in elite athletes.

\section{Other parts in the 5-part series: exercise and pregnancy in recreational and elite athletes}

In addition to this Part 2, there are four other parts of IOC expert group meeting. Part 1: exercise in women planning pregnancy and those who are pregnant. ${ }^{1}$ Parts $3-5$ will be published in 2017 issues of BJSM.

Part 3: Guidance on returning to exercise in the postpartum period.

Part 4: Research directions.

Part 5: Recommendations for health professionals and active women.

\author{
Author affiliations \\ ${ }^{1}$ Department of Sport Medicine, Norwegian School of Sport Sciences, Oslo, Norway \\ ${ }^{2}$ Department of Obstetrics/Gynecology and Women's Health, Saint Louis University, \\ St Louis, Missouri, USA
}

${ }^{3}$ Facultad de Ciencias de la Actividad Física y del Deporte—INEF, Universidad Politécnica de Madrid, Madrid, Spain

${ }^{4}$ Centre for Research on Exercise Physical Activity and Health, School of Human Movement and Nutrition Sciences, University of Queensland, St Lucia, Queensland, Australia

${ }^{5}$ The Poundbury Clinic, King Edward VII Hospital London, Dorchester, UK ${ }^{6}$ Department of Epidemiology, University of North Carolina at Chapel Hill, Chapel Hill, North Carolina, USA

${ }^{7}$ Department of Epidemiology, Gillings School of Global Public Health, Chapel Hill, North Carolina, USA

${ }^{8}$ Department of Sport Sciences, Norwegian School of Sport Sciences, Oslo, Norway ${ }^{9}$ The Swedish School of Sport and Health Sciences, Stockholm, Sweden

${ }^{10}$ Faculty of Biology and Medicine, Institute of Sport Science, University of Lausanne, Lausanne, Switzerland

${ }^{11}$ School of Health Sciences, University of Tampere, Tampere, Finland

${ }^{12}$ R. Samuel McLaughlin Foundation-Exercise and Pregnancy Lab, The University of Western Ontario, London, Ontario, Canada

${ }^{13}$ Department of Obstetrics and Gynecology, University of Utah, Salt Lake City, Utah, USA

${ }^{14}$ Institute of Sport Science, University of Graz, Graz, Austria

${ }^{15}$ Division of Orthopaedic Surgery, Oslo University Hospital, Ullevål, Oslo, Norway

${ }^{16}$ Queens University, Kingston, Ontario, Canada

Contributors $\mathrm{KB}$ conceived the idea and consulted all the other authors in the development of the consensus meeting. All the authors prepared material and submitted it in advance of the inperson meeting in Lausanne. All the authors contributed materially to drafting the various versions of the document and approved the final version.

Funding IOC, 10.13039/501100003965, Internal Funds for Consensus Meetings. Competing interests None declared.

Provenance and peer review Not commissioned; externally peer reviewed.

\section{REFERENCES}

1 Bø K, Artal R, Barakat R, et al. Exercise and pregnancy in recreational and elite athletes: 2016 evidence summary from the IOC expert group meeting, Lausanne. Part 1 -exercise in women planning pregnancy and those who are pregnant. Br J Sports Med 2016:50:571-89.

2 Kruger J, Murphy B, Thompson S. Childbirth and sportswomen: the perceptions of obstetric caregivers. Vision 2006;14:7-15.

3 American College of Obstetricians and Gynecologists. ACOG Practice Bulletin No. 106: Intrapartum fetal heart rate monitoring: nomenclature, interpretation, and general management principles. Obstet Gynecol 2009:114:192-202.

4 McAllister RM. Adaptations in control of blood flow with training: splanchnic and renal blood flows. Med Sci Sports Exerc 1998:30:375-81.

5 Wolfe CD, Patel SP, Campbell EA, et al. Plasma corticotrophin-releasing factor (CRF) in normal pregnancy. Br J Obstet Gynaecol 1988;95:997-1002.

6 Wolfe CD, Patel SP, Linton EA, et al. Plasma corticotrophin-releasing factor (CRF) in abnormal pregnancy. Br J Obstet Gynaecol 1988:95:1003-6.

7 Carpenter MW, Sady SP, Hoegsberg B, et al. Fetal heart rate response to maternal exertion. JAMA 1988:259:3006-9.

8 Artal R, Wiswell R, Romem $Y$, et al. Pulmonary responses to exercise in pregnancy. Am J Obstet Gynecol 1986;154:378-83.

9 Artal R, Romem Y, Paul RH, et al. Fetal bradycardia induced by maternal exercise. Lancet 1984;2:258-60.

10 Szymanski LM, Satin AJ. Strenuous exercise during pregnancy: is there a limit? Am J Obstet Gynecol 2012;207:179.e1-6.

11 Morrow RJ, Ritchie JW, Bull SB. Fetal and maternal hemodynamic responses to exercise in pregnancy assessed by Doppler ultrasonography. Am J Obstet Gynecol 1989:160:138-40.

12 Salvesen $K \AA ̊$, Hem E, Sundgot-Borgen J. Fetal wellbeing may be compromised during strenuous exercise among pregnant elite athletes. Br J Sports Med 2012:46:279-83.

13 The American College of Obstetricians and Gynecologists. Exercise during pregnancy and the postpartum period. ACOG Technical Bulletin Number 189February 1994. Int J Gynaecol Obstet 1994;45:65-70.

14 Committee on Practice Bulletins-Gynecology. The American College of Obstetricians and Gynecologists Practice bulletin no. 150. Early pregnancy loss. Obstet Gynecol 2015;125:1258-67.

15 Madsen $M$, Jørgensen $T$, Jensen $M L$, et al. Leisure time physical exercise during pregnancy and the risk of miscarriage: a study within the Danish National Birth Cohort. BJOG 2007;114:1419-26.

16 Hjollund NH, Jensen TK, Bonde JP, et al. Spontaneous abortion and physical strain around implantation: a follow-up study of first-pregnancy planners. Epidemiology 2000;11:18-23. 
17 Juhl M, Strandberg-Larsen K, Larsen PS, et al. Occupational lifting during pregnancy and risk of fetal death in a large national cohort study. Scand J Work Environ Health 2013;39:335-42.

18 Fenster $\mathrm{L}$, Hubbard AE, Windham GC, et al. A prospective study of work-related physical exertion and spontaneous abortion. Epidemiology 1997;8:66-74.

19 Florack El, Zielhuis GA, Pellegrino JE, et al. Occupational physical activity and the occurrence of spontaneous abortion. Int J Epidemiol 1993;22:878-84.

20 Hagan L, Wong CK. Gait in pregnant women: spinal and lower extremity changes from pre- to postpartum. J Women Health Phys Ther 2010;2:46-56.

21 Schlüssel MM, Souza EB, Reichenheim ME, et al. Physical activity during pregnancy and maternal-child health outcomes: a systematic literature review. Cad Saude Publica 2008;24(Suppl 4):s531-44.

22 Osborn JF, Cattaruzza MS, Spinelli A. Risk of spontaneous abortion in Italy, 1978-1995, and the effect of maternal age, gravidity, marital status, and education. Am J Epidemio/ 2000;151:98-105.

23 Kramer MS, McDonald SW. Aerobic exercise for women during pregnancy. Cochrane Database Syst Rev 2006;CD000180.

24 Siebel AL, Carey AL, Kingwell BA. Can exercise training rescue the adverse cardiometabolic effects of low birth weight and prematurity? Clin Exp Pharmacol Physiol 2012;39:944-57

25 Wiebe HW, Boulé NG, Chari R, et al. The effect of supervised prenatal exercise on fetal growth: a meta-analysis. Obstet Gynecol 2015;125:1185-94.

26 Campbell S. Fetal macrosomia: a problem in need of a policy. Ultrasound Obstet Gynecol 2014;43:3-10.

27 Yu ZB, Han SP, Zhu GZ, et al. Birth weight and subsequent risk of obesity: a systematic review and meta-analysis. Obes Rev 2011;12:525-42.

28 World Health Organization. Preterm birth: fact sheet No 363. 2015. http://www. who.int/mediacentre/factsheets/fs363/en/

29 Blencowe $\mathrm{H}$, Cousens $\mathrm{S}$, Oestergaard MZ, et al. National, regional, and worldwide estimates of preterm birth rates in the year 2010 with time trends since 1990 for selected countries: a systematic analysis and implications. Lancet 2012:379:2162-72.

30 Leet T, Flick L. Effect of exercise on birthweight. Clin Obstet Gynecol 2003;46:423-31.

31 Bonzini M, Coggon D, Palmer KT. Risk of prematurity, low birthweight and pre-eclampsia in relation to working hours and physical activities: a systematic review. Occup Environ Med 2007;64:228-43.

32 Palmer KT, Bonzini M, Bonde JP, et al. Pregnancy: occupational aspects of management: concise guidance. Clin Med 2013;13:75-9.

33 van Beukering MD, van Melick MJ, Mol BW, et al. Physically demanding work and preterm delivery: a systematic review and meta-analysis. Int Arch Occup Environ Health 2014;87:809-34.

34 Savitz DA, Murnane P. Behavioral influences on preterm birth: a review. Epidemiology 2010;21:291-9.

35 Uzendoski AM, Latin RW, Berg KE, et al. Short review: maternal and fetal responses to prenatal exercise. J App/ Sport Sci Res 1989;3:93-100.

36 Lokey EA, Tran ZV, Wells CL, et al. Effects of physical exercise on pregnancy outcomes: a meta-analytic review. Med Sci Sports Exerc 1991;23:1234-9.

37 Berkowitz GS, Papiernik E. Epidemiology of preterm birth. Epidemiol Rev 1993:15:414-43.

38 Lewis $B$, Avery $M$, Jennings $E$, et al. The effect of exercise during pregnancy on maternal outcomes: practical implications for practice. Am J Lifestyle Med 2008;2:441-55

39 De Ver Dye T, Fernandez ID, Rains A, et al. Recent studies in the epidemiologic assessment of physical activity, fetal growth, and preterm delivery: a narrative review. Clin Obstet Gynecol 2003;46:415-22.

40 Hegaard HK, Pedersen BK, Nielsen BB, et al. Leisure time physical activity during pregnancy and impact on gestational diabetes mellitus, pre-eclampsia, preterm delivery and birth weight: a review. Acta Obstet Gynecol Scand 2007;86:1290-6.

41 Domingues MR, Matijasevich A, Barros AJ. Physical activity and preterm birth: a literature review. Sports Med 2009;39:961-75.

42 Takito MY, Benicio MH, Neri Lde C. Physical activity by pregnant women and outcomes for newborns: a systematic review. Rev Saude Publica 2009;43:1059-69.

43 Owe KM, Nystad W, Skjaerven R, et al. Exercise during pregnancy and the gestational age distribution: a cohort study. Med Sci Sports Exerc 2012;44:1067-74.

44 Takito MY, Benicio MH. Physical activity during pregnancy and fetal outcomes: a case-control study. Rev Saude Publica 2010;44:90-101.

45 Domingues MR, Barros AJ, Matijasevich A. Leisure time physical activity during pregnancy and preterm birth in Brazil. Int J Gynaecol Obstet 2008;103:9-15.

46 Juhl M, Andersen PK, Olsen J, et al. Physical exercise during pregnancy and the risk of preterm birth: a study within the Danish National Birth Cohort. Am $J$ Epidemiol 2008;167:859-66.

47 Juhl M, Kogevinas M, Andersen PK, et al. Is swimming during pregnancy a safe exercise? Epidemiology 2010;21:253-8.

48 Sealy-Jefferson S, Hegner K, Misra DP. Linking nontraditional physical activity and preterm delivery in urban African-American women. Womens Health Issues 2014;24:e389-95
49 Nelson K, Lohsoonthorn V, Williams MA. Preterm delivery risk in relation to maternal occupational and leisure time physical activity among Thai women. Asian Biomed (Res Rev News) 2009;3:267-77.

50 Guendelman S, Pearl M, Kosa JL, et al. Association between preterm delivery and pre-pregnancy body mass (BMI), exercise and sleep during pregnancy among working women in Southern California. Matern Child Health J 2013;17:723-31.

51 Tinloy J, Chuang $\mathrm{CH}$, Zhu J, et al. Exercise during pregnancy and risk of late preterm birth, cesarean delivery, and hospitalizations. Womens Health Issues 2014;24:e99-104.

52 Currie LM, Woolcott CG, Fell DB, et al. The association between physical activity and maternal and neonatal outcomes: a prospective cohort. Matern Child Health J 2014:18:1823-30.

53 Clapp JF III. The course of labor after endurance exercise during pregnancy. Am J Obstet Gynecol 1990;163(Pt 1):1799-805.

54 Evenson KR, Siega-Riz AM, Savitz DA, et al. Vigorous leisure activity and pregnancy outcome. Epidemiology 2002;13:653-9.

55 Barakat R, Pelaez M, Montejo R, et al. Exercise throughout pregnancy does not cause preterm delivery: a randomized, controlled trial. J Phys Act Health 2014;11:1012-17

56 Barakat $R$, Perales $M$, Bacchi $M$, et al. A program of exercise throughout pregnancy. Is it safe to mother and newborn? Am J Health Promot 2014;29:2-8.

57 Price BB, Amini SB, Kappeler K. Exercise in pregnancy: effect on fitness and obstetric outcomes-a randomized trial. Med Sci Sports Exerc 2012:44:2263-9.

58 Haakstad LA, Bø K. Effect of regular exercise on prevention of excessive weight gain in pregnancy: a randomised controlled trial. Eur J Contracept Reprod Health Care 2011;16:116-25.

59 Haakstad LA, Bø K. Exercise in pregnant women and birth weight: a randomized controlled trial. BMC Pregnancy Childbirth 2011;11:66.

60 Cavalcante SR, Cecatti JG, Pereira RI, et al. Water aerobics II: maternal body composition and perinatal outcomes after a program for low risk pregnant women. Reprod Health 2009;6:1.

61 Pinzon DC, Zamora K, Martinez $\mathrm{JH}$, et al. Type of delivery and gestational age is not affected by pregnant Latin-American women engaging in vigorous exercise: a secondary analysis of data from a controlled randomized trial. Rev Salud Publica (Bogota) 2012;14:731-43.

62 American College of Obstetricians and Gynecologists. Committee Opinion No. 644: The Apgar score. Obstet Gynecol 2015;126:e52-5.

63 Montgomery KS. Apgar scores: examining the long-term significance. J Perinat Educ 2000;9:5-9.

64 Murtezani A, Pacarada M, Ibraimi Z, et al. The impact of exercise during pregnancy on neonatal outcomes: a randomized controlled trial. J Sports Med Phys Fitness 2014;54:802-8

65 Osterman MJ, Martin JA. Recent declines in induction of labor by gestational age. NCHS Data Brief 2014;155:1-8.

66 Friedman AM, Ananth CV, Prendergast $\mathrm{E}$, et al, Variation in and factors associated with use of episiotomy. JAMA 2015;313:197-9.

67 Vogel JP, Gülmezoglu AM, Hofmeyr GJ, et al. Global perspectives on elective induction of labor. Clin Obstet Gynecol 2014;57:331-42.

68 Graham ID, Carroli G, Davies C, et al. Episiotomy rates around the world: an update. Birth 2005:32:219-23.

69 Frankman EA, Wang L, Bunker $\mathrm{CH}$, et al. Episiotomy in the United States: has anything changed? Am J Obstet Gynecol 2009;200:573.e1-7.

70 Carroli G, Mignini L. Episiotomy for vaginal birth. Cochrane Database Syst Rev 2009;CD000081.

71 Osterman MJ, Martin JA. Epidural and spinal anesthesia use during labor: 27-state reporting area, 2008. Natl Vital Stat Rep 2011:59:1-13, 16

72 Meuser T, Wiese R, Molitor D, et al. [A survey of labour pain management in Germany]. Schmerz 2008;22:184-90.

73 Tveit TO, Halvorsen A, Rosland JH. Analgesia for labour: a survey of Norwegian practice - with a focus on parenteral opioids. Acta Anaesthesiol Scand 2009:53:794-9.

74 Moore LE, Rayburn WF. Elective induction of labor. Clin Obstet Gynecol 2006:49:698-704

75 Domenjoz I, Kayser B, Boulvain M. Effect of physical activity during pregnancy on mode of delivery. Am J Obstet Gynecol 2014:211:401.e1-11.

76 Kruger JA, Dietz HP, Murphy BA. Pelvic floor function in elite nulliparous athletes. Ultrasound Obstet Gynecol 2007:30:81-5.

77 Kruger JA, Murphy BA, Heap SW. Alterations in levator ani morphology in elite nulliparous athletes: a pilot study. Aust N Z J Obstet Gynaecol 2005;45:42-7.

78 Barakat R, Ruiz JR, Stirling JR, et al. Type of delivery is not affected by light resistance and toning exercise training during pregnancy: a randomized controlled trial. Am J Obstet Gynecol 2009;201:590.e1-6.

79 Salvesen KA, Stafne SN, Eggebo TM, et al. Does regular exercise in pregnancy influence duration of labor? A secondary analysis of a randomized controlled trial. Acta Obstet Gynecol Scand 2014;93:73-9. 
80 Bø K, Hilde G, Staer-Jensen J, et al. Does general exercise training before and during pregnancy influence the pelvic floor 'opening' and delivery outcome? A 3D/4D ultrasound study following nulliparous pregnant women from mid-pregnancy to childbirth. Br J Sports Med 2015;49:196-9.

81 Bø K, Fleten C, Nystad W. Effect of antenatal pelvic floor muscle training on labor and birth. Obstet Gynecol 2009;113:1279-84.

82 Bø K, Hilde G, Jensen JS, et al. Too tight to give birth? Assessment of pelvic floor muscle function in 277 nulliparous pregnant women. Int Urogynecol J 2013;24:2065-70

83 Kemp E, Kingswood CJ, Kibuka M, et al. Position in the second stage of labour for women with epidural anaesthesia. Cochrane Database Syst Rev 2013; CD008070.

84 Laughon SK, Berghella V, Reddy UM, et al. Neonatal and maternal outcomes with prolonged second stage of labor. Obstet Gynecol 2014;124:57-67.

85 Senécal J, Xiong $X$, Fraser WD, et al. Effect of fetal position on second-stage duration and labor outcome. Obstet Gynecol 2005; 105:763-72.

86 Verdiales M, Pacheco C, Cohen WR. The effect of maternal obesity on the course of labor. J Perinat Med 2009;37:651-5.

87 Carlhäll S, Källén K, Blomberg M. Maternal body mass index and duration of labor. Eur J Obstet Gynecol Reprod Biol 2013;171:49-53.

88 Perales M, Calabria I, Lopez C, et al. Regular exercise throughout pregnancy is associated with a shorter first stage of labor. Am J Health Promot 2016:30:149-54.

89 Kardel KR, Johansen B, Voldner N, et al. Association between aerobic fitness in late pregnancy and duration of labor in nulliparous women. Acta Obstet Gynecol Scand 2009;88:948-52.

90 World Health Organization. The Global Numbers and Costs of Additionally Needed and Unnecessary Caesarean Sections Performed per Year: Overuse as a Barrier to Universal Coverage. 2010. http://www.who.int/healthsystems/topics/financing/ healthreport/30C-sectioncosts.pdf

91 Beckmann CR, Beckmann CA. Effect of a structured antepartum exercise program on pregnancy and labor outcome in primiparas. J Reprod Med 1990;35:704-9.

92 Bovbjerg ML, Siega-Riz AM. Exercise during pregnancy and cesarean delivery: North Carolina PRAMS, 2004-2005. Birth 2009;36:200-7.

93 Hall DC, Kaufmann DA. Effects of aerobic and strength conditioning on pregnancy outcomes. Am J Obstet Gynecol 1987;157:1199-203.

94 Dumith SC, Domingues MR, Mendoza-Sassi RA, et al. Physical activity during pregnancy and its association with maternal and child health indicators. Rev Saude Publica 2012:46:327-33.

95 Gawade P, Pekow P, Markenson G, et al. Physical activity before and during pregnancy and duration of second stage of labor among Hispanic women. J Reprod Med 2009;54:429-35.

96 Bayrampour $\mathrm{H}$, Heaman M. Advanced maternal age and the risk of cesarean birth: a systematic review. Birth 2010;37:219-26.

97 Kominiarek MA, Vanveldhuisen P, Hibbard J, et al. The maternal body mass index: a strong association with delivery route. Am J Obstet Gynecol 2010;203:264.e1-7.

98 Kominiarek MA, VanVeldhuisen P, Gregory K, et al. Intrapartum cesarean delivery in nulliparas: risk factors compared by two analytical approaches. J Perinatol 2015;35:167-72.

99 Poyatos-León R, García-Hermoso A, Sanabria-Martínez G, et al. Effects of exercise during pregnancy on mode of delivery: a meta-analysis. Acta Obstet Gynecol Scand 2015:94:1039-47.

100 Herschorn S. Female pelvic floor anatomy: the pelvic floor, supporting structures, and pelvic organs. Rev Urol 2004;6(Suppl 5):S2-10.

101 Lien KC, Mooney B, DeLancey J0, et al. Levator ani muscle stretch induced by simulated vaginal birth. Obstet Gynecol 2004;103:31-40.

102 Schwertner-Tiepelmann N, Thakar R, Sultan AH, et al. Obstetric levator ani muscle injuries: current status. Ultrasound Obstet Gynecol 2012;39:372-83.

103 van Veelen GA, Schweitzer KJ, van Delft K, et al. Diagnosing levator avulsions after first delivery by tomographic ultrasound: reliability between observers from different centers. Int Urogynecol J 2014;25:1501-6.
104 Hilde G, Staer-Jensen J, Siafarikas F, et al. How well can pelvic floor muscles with major defects contract? A cross-sectional comparative study 6 weeks after delivery using transperineal 3D/4D ultrasound and manometer. BJOG 2013;120:1423-9.

105 Durnea CM, Khashan AS, Kenny LC, et al. Prevalence, etiology and risk factors of pelvic organ prolapse in premenopausal primiparous women. Int Urogynecol J 2014;25:1463-70.

106 DeLancey J0, Kearney R, Chou Q, et al. The appearance of levator ani muscle abnormalities in magnetic resonance images after vaginal delivery. Obstet Gynecol 2003;101:46-53.

107 Dietz HP, Lanzarone V. Levator trauma after vaginal delivery. Obstet Gynecol 2005; 106:707-12.

108 Dietz HP, Franco AV, Shek KL, et al. Avulsion injury and levator hiatal ballooning: two independent risk factors for prolapse? An observational study. Acta Obstet Gynecol Scand 2012;91:211-14.

109 Albrich SB, Laterza RM, Skala C, et al. Impact of mode of delivery on levator morphology: a prospective observational study with three-dimensional ultrasound early in the postpartum period. BJOG 2012;119:51-60.

110 Chan SS, Cheung RY, Yiu AK, et al. Prevalence of levator ani muscle injury in Chinese women after first delivery. Ultrasound Obstet Gynecol 2012;39:704-9.

111 Stær-Jensen J, Siafarikas F, Hilde G, et al. Postpartum recovery of levator hiatus and bladder neck mobility in relation to pregnancy. Obstet Gynecol 2015;125:531-9.

112 van Delft $K$, Sultan AH, Thakar R, et al. The relationship between postpartum levator ani muscle avulsion and signs and symptoms of pelvic floor dysfunction. BJOG 2014;121:1164-72.

113 Dietz HP, Simpson JM. Levator trauma is associated with pelvic organ prolapse. BJOG 2008;115:979-84.

114 DeLancey JO, Morgan DM, Fenner DE, et al. Comparison of levator ani muscle defects and function in women with and without pelvic organ prolapse. Obstet Gynecol 2007;109(Pt 1):295-302.

115 Kearney R, Miller JM, Ashton-Miller JA, et al. Obstetric factors associated with levator ani muscle injury after vaginal birth. Obstet Gynecol 2006;107:144-9.

116 Heilbrun ME, Nygaard IE, Lockhart ME, et al. Correlation between levator ani muscle injuries on magnetic resonance imaging and fecal incontinence, pelvic organ prolapse, and urinary incontinence in primiparous women. Am J Obstet Gynecol 2010;202:488.e1-6.

117 Shek KL, Dietz HP. Intrapartum risk factors for levator trauma. BJOG 2010;117:1485-92.

118 Royal College of Obstetricians and Gynaecologists. The Management of Third- and Fourth-Degree Perineal Tears: Green-top Guideline No. 29. 2015. https://www. rcog.org.uk/en/guidelines-research-services/guidelines/gtg29/

119 Borin LC, Nunes FR, Guirro EC. Assessment of pelvic floor muscle pressure in female athletes. $P M R$ 2013;5:189-93.

120 Fenner DE, Genberg B, Brahma $\mathrm{P}$, et al. Fecal and urinary incontinence after vaginal delivery with anal sphincter disruption in an obstetrics unit in the United States. Am J Obstet Gynecol 2003;189:1543-9.

121 Dudding TC, Vaizey CJ, Kamm MA. Obstetric anal sphincter injury: incidence, risk factors, and management. Ann Surg 2008:247:224-37.

122 Abbott $\mathrm{D}$, Atere-Roberts $\mathrm{N}$, Williams $\mathrm{A}$, et al. Obstetric anal sphincter injury. BMJ 2010;341:c3414

123 Gurol-Urganci I, Cromwell DA, Edozien LC, et al. Third- and fourth-degree perinea tears among primiparous women in England between 2000 and 2012: time trends and risk factors. BJOG 2013:120:1516-25.

124 Kapoor DS, Thakar R, Sultan AH. Obstetric anal sphincter injuries: review of anatomical factors and modifiable second stage interventions. Int Urogynecol $J$ 2015;26:1725-34.

125 Evers EC, Blomquist JL, McDermott KC, et al. Obstetrical anal sphincter laceration and anal incontinence 5-10 years after childbirth. Am J Obstet Gynecol 2012;207:425.e1-6.

126 Voldner N, Frøslie KF, Haakstad LA, et al. Birth complications, overweight, and physical inactivity. Acta Obstet Gynecol Scand 2009;88:550-5. 